\title{
Plasma-chemical modification of concrete processed by colorific metal salts
}

\author{
Diana Olegovna Bondarenko \\ Department of material science and material \\ technology \\ Belgorod State Technological University named \\ after V.G. Shoukhov \\ BSTU named after V.G. Shoukhov \\ 308012, Kostukov St., 46 \\ di_bondarenko@mail.ru \\ Nadezda Ivanovna Bondarenko \\ Department of glass and ceramics technology \\ Belgorod State Technological University named \\ after V.G. Shoukhov \\ BSTU named after V.G. Shoukhov \\ 308012, Kostukov St., 46 \\ Russia, Belgorod \\ bondarenko-71@mail.ru
}

\author{
Vasiliy Stepanovich Bessmertnyi \\ Department of glass and ceramics technology \\ Belgorod State Technological University named \\ after V.G. Shoukhov \\ BSTU named after V.G. Shoukhov \\ 308012, Kostukov St., 46 \\ vbessmertnyi@mail.ru
}

\author{
Nikolay Mikhailovich Burlakov \\ Department of glass and ceramics technology \\ Belgorod State Technological University named \\ after V.G. Shoukhov \\ BSTU named after V.G. Shoukhov \\ 308012, Kostukov St., 46 \\ mcbnm@yandex.ru
}

\begin{abstract}
The most important task at the present stage of the formation of modern society is the intensive development of the national economy on the basis of the latest achievements of science and technology. The building materials industry in the Russian Federation is one of the most energy-intensive industries. In this regard, reducing energy costs and environmental pressure on nature through the introduction of alternative energy sources in production is relevant for the state. Previously, it was proved that plasma-chemical modification contributes to the increase of water resistance, acid resistance, alkali resistance, microhardness of the fused (glazed) face layer, and also allows one to expand the possibilities of obtaining various types of decor. However, plasma-chemical modification leads to significant thermal shock, dehydration of hydrosilicates in cement stone and its softening, which reduces the operational parameters of the protective and decorative coating on concrete products, in particular, adhesion strength and frost resistance. Using a plasma jet will significantly intensify the formation of vitreous protective and decorative coating with increased technical and operational performance, and the use of various industrial waste and color salts will provide an opportunity to significantly expand the base for obtaining a variety of types of decor on the face of the concrete. In connection with the foregoing, the development of an effective technology for
\end{abstract}

the production of protective decorative coatings on concrete products is a relevant area of research. The purpose of the work is the development of protective and decorative coatings on products made of concrete using recycled materials and coloring metal salts. The macro and microstructure of the protective and decorative coating and the surface layer treated with a plasma jet, the microhardness of the fused layer of fine-grained concrete after plasma-chemical modification are given in the article. The regularities of the formation of the structure of protective and decorative coatings on concrete with the use of coloring salts are substantiated.

Keywords - Plasma-chemical modification, metal salts, protective-decorative coating, plasma jet, face layer.

\section{INTRODUCTION}

Plasma processes of material processing allow creating innovative technologies, reducing the production cycle and increasing the competitiveness of manufactured products [15].

When plasma technologies are used due to high plasma temperatures, about $7000-10000{ }^{\circ} \mathrm{C}$, the equilibrium of the reactions shifts towards high temperatures, the rate of chemical reactions sharply increases, and the classical laws of thermodynamics cease to work. 
In the technology of technical ceramics and refractories, an effective technology for melting pure and high-heat refractory materials has been developed [6]. At present, the technology of synthesis of silicate glasses in a plasma discharge from the vapor phase is widespread in the world practice [7].

Glass plasma coatings with high mechanical and chemical resistance are obtained by the method of plasma spraying [8]. In this case, the factor that forms the quality of coatings is the process of crystallization of glasses [9].

Obtaining decorative coatings on glass products using the method of plasma spraying is less energy intensive, environmentally friendly technological process, which allows to significantly reduce the cost of production in comparison with traditional technologies.

In connection with the fact that the development of new plasma technologies in the building materials industry is an actual research direction.

Most native and foreign experts came to the conclusion that glaze coatings provide durability of artificial stone materials and products based on mineral binders. This proves the sustainability of such finishing. However, the problem of high-temperature finishing of concrete (reinforced concrete) products, which prevail in modern construction, requires effective solutions, not only for the development of special compositions for finishing (including vitreous) coatings, but also for creating new ones, improving the existing methods of applying and fixing the finishing layer, and also the design of special technical means. All this points to the need to highlight the problem of high-temperature finishing of concrete as one of the most important areas of development of modern technology. At the same time, nowadays a considerable experience has been accumulated in the application of various methods of high-temperature finishing of this material.

Known methods for high-temperature finishing of concrete products can be divided into two groups: without pre-coating and applying a finishing layer on the surface of the product. The first group includes methods associated with fusion directly on the surface of products, including preimpregnation with inorganic binders and solutions of metal salts (to expand the color gamma of the resulting vitreous coating).

The second group includes such methods of hightemperature finishing as glazing (enamelling), fusion of crushed glass (glass granules), spraying of glass material particles, fusion of previously deposited paste layers, metallization [10].

There are several different technologies for coating the surface of concrete products with a glass layer (glaze). A method is known for finishing building materials, including concrete, by applying a layer of glass granules to their surface, followed by fusion, and the granules are treated with a liquid glass with a colouring matter before application. Crushed window and container glasses were used as glassy granules.
Long-lasting and stable coating of the surfaces of reinforced concrete products is obtained by a method providing for application to the concrete surface of an underglaze layer from a mixture of cement and quartz powder, which after hardening is covered with glaze slip and burned at a temperature of $850-950{ }^{\circ} \mathrm{C}$. According to the technology given in [11], the glazing of concrete products is performed using a special heat-resistant underglaze layer. After steam treatment the glaze suspension is sprayed onto the heat-resistant layer, dried and fused at a temperature of $900-950^{\circ} \mathrm{C}$.

Researchers of BSTU named after V.G. Shukhov [5] used different ground crushed glasses (blue, green, colorless) to glaze the surface of concrete. As a mixture for the formation of the intermediate layer, alumina cement and ground chamotte were used. An electric arc plasma jet UPU$8 \mathrm{M}$ served as a high-temperature source.

The coating on the front side of concrete products was carried out with a plasma modified burner of the electric arc plasma jet UPU-8M. The crushed glass was ground in a ball mill and subjected to screening on the sieves for fractions corresponding to the plasma spraying conditions. During plasma treatment there are changes in the structure and properties of the surface layer of concrete. This significantly reduces the performance characteristics of concrete products, in particular, the adhesion strength of the coating to the substrate. It is envisaged that before the plasma treatment an intermediate layer is formed on the front surface, consisting of a mixture of heat-resistant concrete and ground chamotte.

Intermediate layer prevents the dehydration of the surface layer of concrete and reduces the rigidity of thermal shock during the plasma spraying of glass powders. For this purpose the authors developed a technology for obtaining an intermediate layer that includes grinding and sieving chamotte fractions and further mixing of the fractionated chamotte powder with aluminous cement. The resulting mixture was tempered with water and applied to the concrete surface.

Oxides of titanium, chromium, cobalt and other were used to expand the color spectrum of the vitreous coating of concrete. Different concentrations of titanium oxide salts make it possible to obtain a wide range of colors from pearl to brown.

Preliminary impregnation of concrete products with nitric acid salts of nickel, cobalt, copper and manganese, followed by fusion of their surface, makes it possible, according to the author [12], to obtain an almost unlimited color gamut.

For the coloring the front surface of concrete, the dyeing salts or oxides of copper, cobalt and chromium metals were introduced into the mixture for the preparation of concrete products with water in the form of $0.5-2.0 \%$ aqueous solution or by the capillary suction method when applied to the surface of the products before fusion.

In the work it is suggested to combine impregnation of products from concrete with solutions of salts and glazing. 
So, previously the surface of concrete was impregnated with a aqueous solution of nitric acid salt, and then a suspension of transparent colorless glaze was applied to the dried surface of the product, which was dried and fused. As a result, the glaze coating had an "internal" colored layer [12].

\section{Results and discussions}

The object of the study was portland cement of grade $M$ 400. For testing, concrete samples prepared in advance from the following raw materials were molded:

- Portland cement according to State Standard 31108-2016.

- Sand of Novoselovsky deposit according to State Standard 22551-77.

- Water according to State Standard 23732-2011.

The ratio of portland cement and quartz sand was 1:3, the water-cement ratio $(\mathrm{W} / \mathrm{C})-0.4$.

As a component for the production of protective and decorative coatings, crushed colorless container glasses and household glasses of different fractional composition $(0.25-$ $2.5 \mathrm{~mm}$ ) were used. The chemical composition of the materials studied in the work is presented in Table I.

Nitric acid salts were used for the preparation of aqueous coloring solutions:

- Cobalt $\mathrm{CoCl}_{2} \cdot 6 \mathrm{H}_{2} \mathrm{O}$ (State Standard 4525-77);

- Nickel $\mathrm{NiCl}_{2} \cdot 6 \mathrm{H}_{2} \mathrm{O}$ (State Standard 4038-79);

- Copper $\mathrm{CuCl}_{2} \cdot 2 \mathrm{H}_{2} \mathrm{O}$ (State Standard 4167-74).

TABLE I. THE CHEMICAL COMPOSITION OF STUDIED MATERIALS

\begin{tabular}{|c|c|c|c|c|c|c|c|c|c|}
\hline \multirow[t]{2}{*}{ Name } & \multicolumn{9}{|c|}{ Weight content, mass \% } \\
\hline & $\begin{array}{l}\mathrm{Si} \\
\mathrm{O}_{2} \\
\end{array}$ & $\begin{array}{l}\mathrm{Al}_{2} \\
\mathrm{O}_{3}\end{array}$ & $\begin{array}{l}\mathrm{Ca} \\
\mathrm{O} \\
\end{array}$ & $\begin{array}{l}M g \\
O\end{array}$ & $\begin{array}{l}F e \\
{ }_{x} O_{x}\end{array}$ & $\begin{array}{l}\mathrm{Na} \\
{ }_{2} \mathrm{O} \\
\end{array}$ & $\begin{array}{l}K_{2} \\
O\end{array}$ & $\begin{array}{l}\mathrm{B}_{2} \\
\mathrm{O}_{3}\end{array}$ & $\begin{array}{l}\mathrm{SO} \\
3\end{array}$ \\
\hline $\begin{array}{l}\text { Portland } \\
\text { cement }\end{array}$ & 24.0 & 7.0 & 64.65 & 1.35 & 2.0 & - & - & - & 1.0 \\
\hline $\begin{array}{l}\text { Colorless } \\
\text { glass }\end{array}$ & 68.4 & 6.3 & 9.3 & - & 0.05 & 16.0 & - & - & - \\
\hline $\begin{array}{l}\text { Household } \\
\text { glass colored } \\
\text { with } \\
\text { chromium } \\
\mathrm{Cr}_{2} \mathrm{O}_{3}-0.5 \\
\%\end{array}$ & 72.7 & - & 8.8 & - & 0.05 & 15.0 & 2.0 & 1.0 & - \\
\hline $\begin{array}{l}\begin{array}{l}\text { Household } \\
\text { glass colored }\end{array} \\
\text { with cobalt } \\
\mathrm{CoO}-0.1 \%\end{array}$ & 68.6 & 6.3 & 9.3 & - & 0.05 & 14.0 & 1.0 & - & - \\
\hline
\end{tabular}

As a filler for the formation of the underlayment heatresistant layer, a crushed high-alumina lightweight material was used.

The underlayer must prevent the surface of the concrete products from the dehydration processes during plasma fusion.
The microstructure was examined by means of scanning electron microscopy using a TESCAN MIRA 3 LMU scanning electron microscope.

The paper presents the results of studies of the effect of plasma-chemical modification on the microstructure of a surface layer of fine-grained concrete.

To conduct studies, Portland cement concrete samples of $30 \times 30 \times 30 \mathrm{~mm}$ were molded. When molding the "face up" samples, a litter layer was prepared from a floured highalumina lightweight material. The layer was applied and compacted during the formation of fine-grained concrete $(\mathrm{W} / \mathrm{C}=0.4)$. In order to increase the adhesion strength of the coating to the basement and uniform distribution of the material, freshly molded samples were treated for 10 minutes in the ultrasonic bath PSB-5735-05 220V $\pm 5 \% 50$ $60 \mathrm{~Hz}$.

After hardening in air during 28 days, the samples were removed from the molds and treated with salts of cobalt $\left(\mathrm{CoCl}_{2} \cdot 6 \mathrm{H}_{2} \mathrm{O}\right)$, nickel $\left(\mathrm{NiCl}_{2} \cdot 6 \mathrm{H}_{2} \mathrm{O}\right)$ and copper $\left(\mathrm{CuCl}_{2} \cdot 2 \mathrm{H}_{2} \mathrm{O}\right)$. Aqueous solutions of the salts were prepared at a salt:water ratio of $1: 1$, respectively. After impregnation of the samples with salts, the samples were dried in an oven and fused with a plasma jet at a temperature of $5000^{\circ} \mathrm{C}$. In the process of plasma fusion, vitreous coatings were formed:

- dark blue color from cobalt salts;

- gray colors of various shades from nickel salts;

- orange-red from the salts of copper.

The microstructure of protective and decorative coating impregnated with salts of nickel, cobalt and copper is presented in Fig. 1-3.

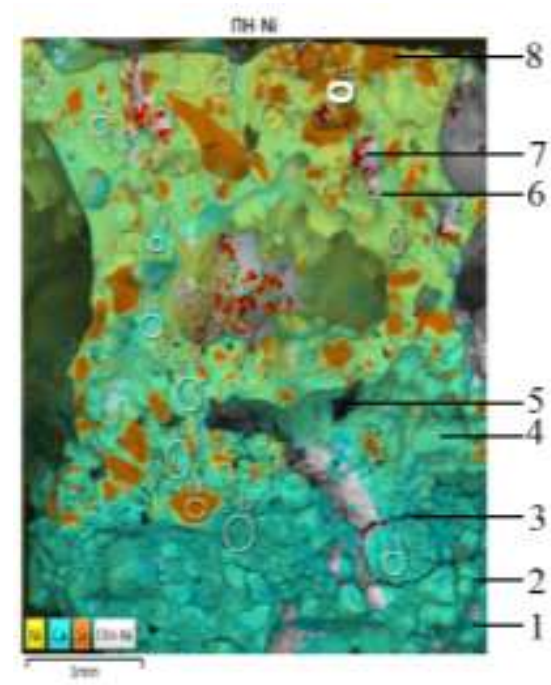

Fig. 1. Microstructure of the coating after plasma fusion from nickel salts on fine-grained concrete: 1 - matrix of fine-grained concrete; 2 - grains of ground high alumina lightweight material; 3 - cracks; 4 - intermediate zone; 5 - pores; 6 - vitreous protective and decorative coating; 7 - gas inclusions; 8 - areas of inhomogeneity 


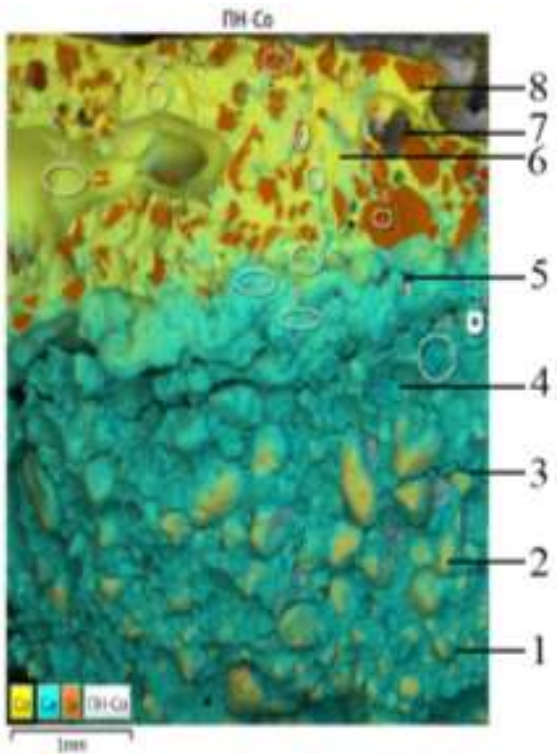

Fig. 2. Microstructure of the coating after plasma fusion from cobalt salts on fine-grained concrete: 1 - matrix of fine-grained concrete; 2 - grains of ground high alumina lightweight material; 3 - cracks; 4 - intermediate zone; 5 - pores; 6 - vitreous protective and decorative coating; 7 - gas inclusions; 8 - areas of inhomogeneity

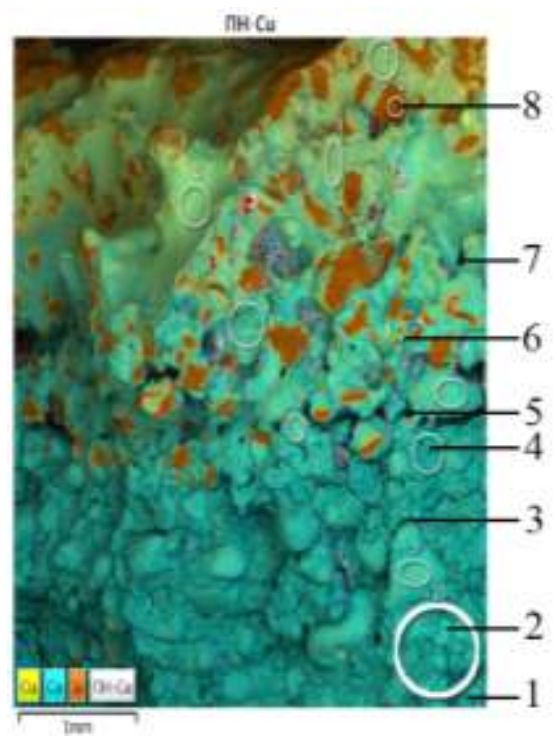

Fig. 3. Microstructure of the coating after plasma fusion from copper salts on fine-grained concrete: 1 - matrix of fine-grained concrete; 2 - grains of ground high alumina lightweight material; 3 - cracks; 4 - intermediate zone; 5 - pores; 6 - vitreous protective and decorative coating; 7 - gas inclusions; 8 - areas of inhomogeneity

In the sample after plasma fusion (Fig. 1-3), three clear areas can be distinguished: a fused layer, an intermediate layer and a layer of fine-grained concrete. In the fused layer, inhomogeneity areas and gas inclusions are observed. In the examined layers, there are channel and closed pores and microcracks, as well as incompletely dissolved grains of the ground high alumina lightweight material.

Energy dispersive spectrometry of coatings with salts is presented in Fig. 4.
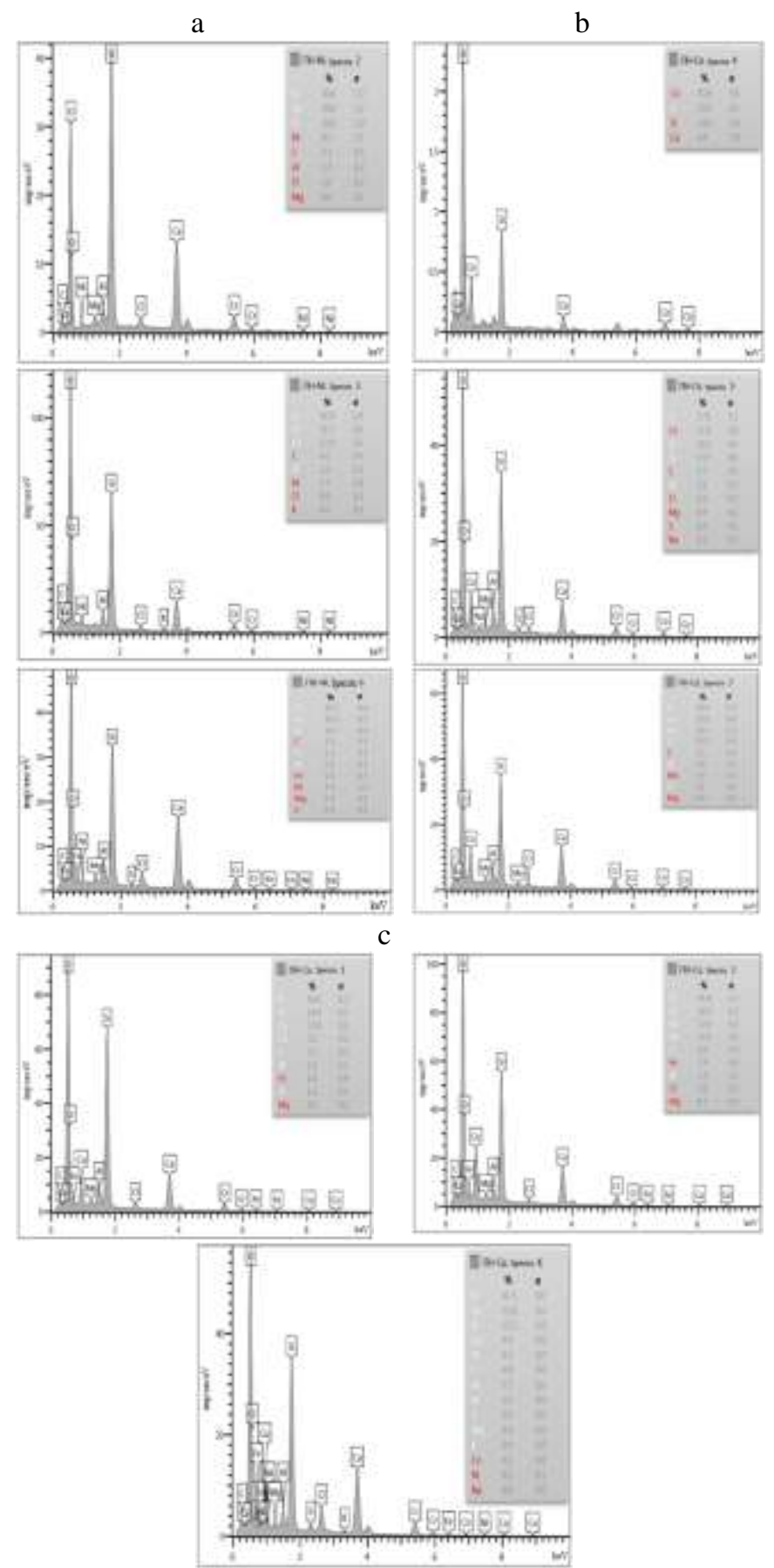

Fig. 4. Energy dispersive spectrometry of coatings with salts: $a-$ nickel; $b-$ cobalt; c - copper

Analysis of the content of nickel, cobalt and copper salts shows that some of the salts in the upper surface layer are removed by thermal diffusion and evaporation. The highest concentration of salts is observed in the middle of the fused layer and decreases in the intermediate layer.

The distribution of $\mathrm{C}, \mathrm{O}, \mathrm{Si}, \mathrm{Cl}, \mathrm{K}, \mathrm{Ca}, \mathrm{Fe}, \mathrm{Mg}, \mathrm{Al}, \mathrm{S}$, $\mathrm{Cr}, \mathrm{Ni}, \mathrm{Co}$ and $\mathrm{Cu}$ over the thickness of the fused and deep layer in fine-grained concrete after plasma fusion is shown in Fig. 5-7. 

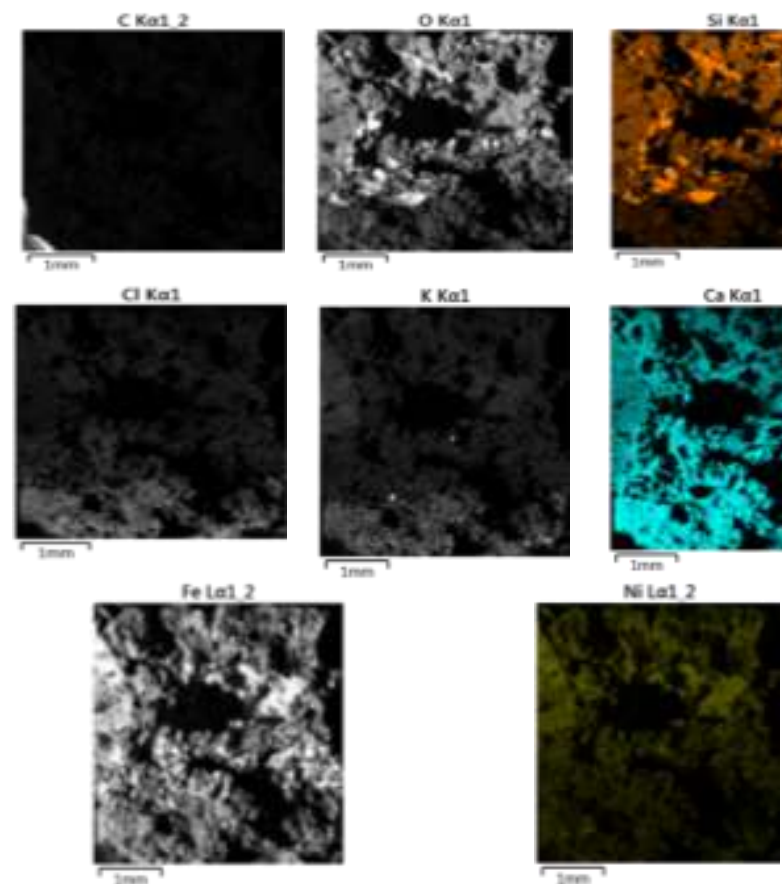

Fig. 5. Distribution of C, O, Si, Cl, K, Ca, Fe, and Ni over the thickness of the fused and deep layer in plasma-fused concrete
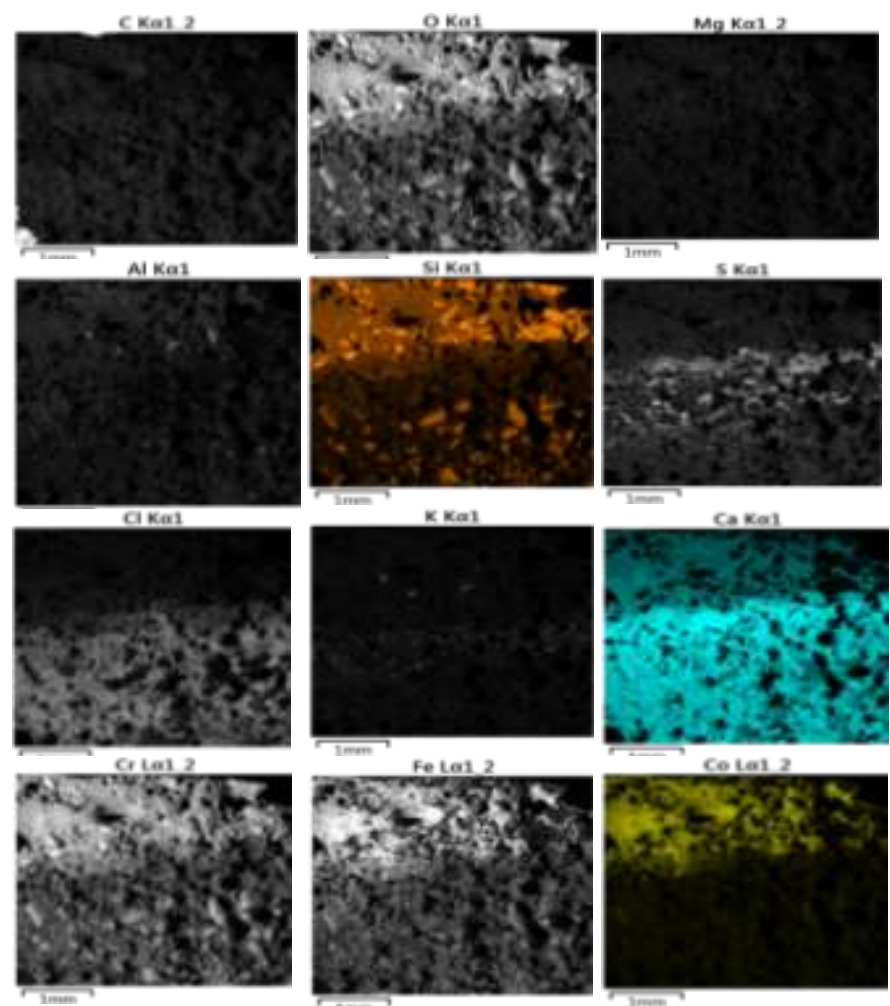

Fig. 6. Distribution of $\mathrm{C}, \mathrm{O}, \mathrm{Mg}, \mathrm{Al}, \mathrm{Si}, \mathrm{S}, \mathrm{Cl}, \mathrm{K}, \mathrm{Ca}, \mathrm{Cr}, \mathrm{Fe}$ and $\mathrm{Co}$ over the thickness of the fused and deep layer in plasma-fused fine-grained concrete
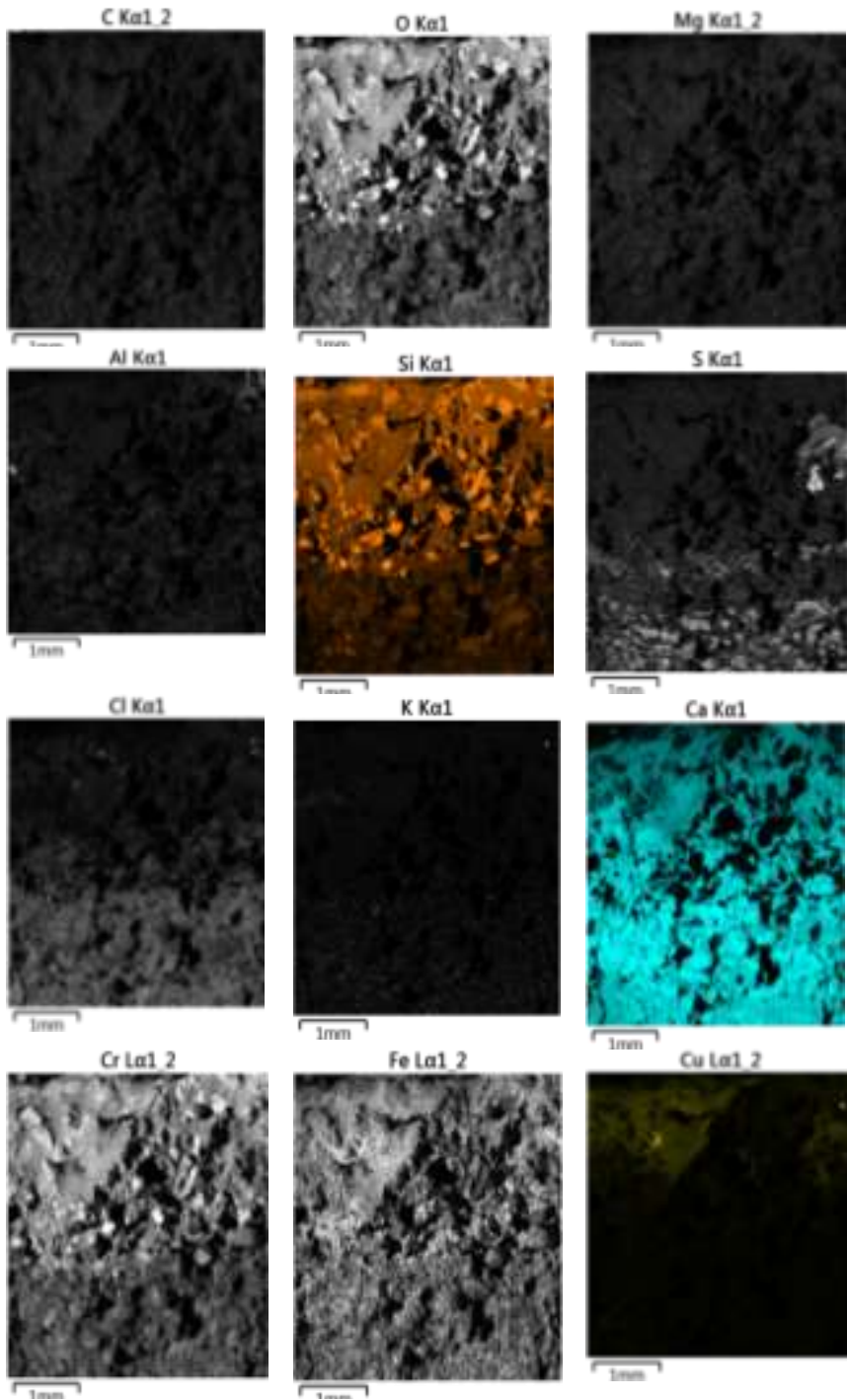

$\sqrt{\operatorname{lnm}} \cos \tan 2$

Fig. 7. Distribution of $\mathrm{C}, \mathrm{O}, \mathrm{Mg}, \mathrm{Al}, \mathrm{Si}, \mathrm{S}, \mathrm{Cl}, \mathrm{K}, \mathrm{Ca}, \mathrm{Cr}, \mathrm{Fe}$ and $\mathrm{Cu}$ in the thickness of the fused and deep layer in plasma-fused fine-grained concrete

The temperature of the plasma jet of about $5000{ }^{\circ} \mathrm{C}$ warmed up the crystalline phase to high temperatures, which melted intensely. Under the influence of high temperatures, the content of alkaline and alkaline-earth oxides decreased from the melted material due to thermal diffusion and evaporation.

High temperatures of the plasma torch led not only to the melting of crystalline phases, but also to dehydration in a layer of fine-grained concrete with the formation of microcracks.

Thus, the conducted studies allow us to establish factors that affect a significant reduction in the strength of adhesion of the fused layer to the basement and the use of highalumina lightweight material has reduced the number of cracks in the dehydration layer.

The results of studies of the influence of the heatresistant layer with color salts on the colorability of finegrained concrete during its plasma-chemical modification are shown in Fig. 8, 9. 
a

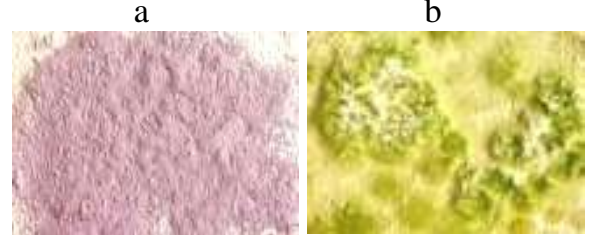

Fig. 8. Samples before fusion with preliminary impregnation with solutions of nitric acid salts and copper chloride: $\mathrm{a}$ - cobalt; $\mathrm{b}$ - nickel; $\mathrm{c}$ - copper

Samples of fine-grained concrete (Fig. 8) were evenly impregnated with solutions of nitrate salts. The crystallization of the surface was observed on the sample with the solution of the nickel salt.
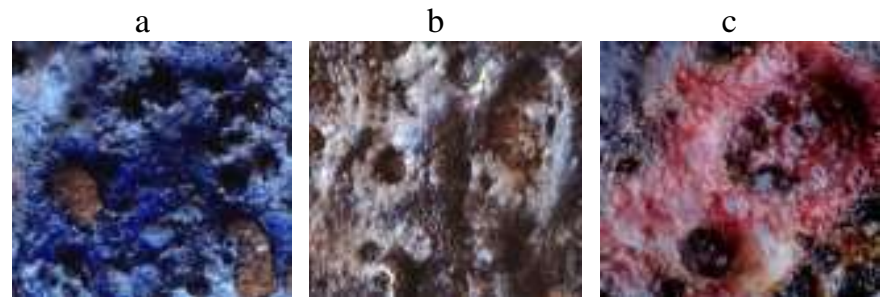

Fig. 9. Samples after fusion

in Fig. 9 samples that have undergone fusion have a bright color, corresponding to that of the selected salt solutions. Surface exposure was observed on the front of the sample. This is explained by the action of surface tension forces. Thus, the higher the temperature, the lower the surface tension. Since the surface energy depends on the surface area, any liquid phase is energetically disadvantageous to have a large surface area.
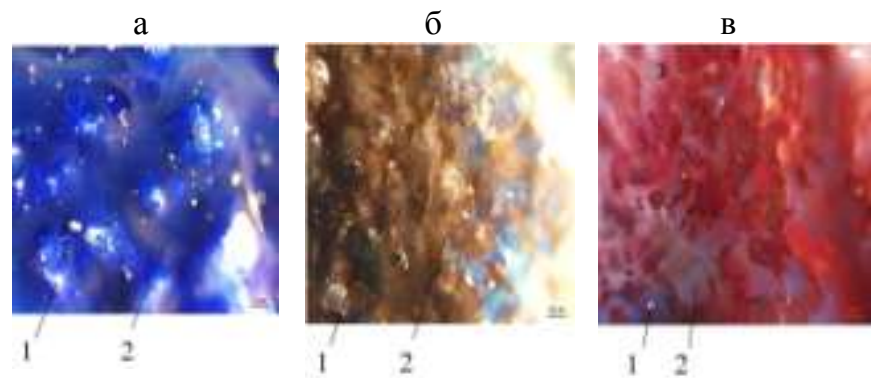

Fig. 10. Results of examination of the surface in transmitted light: 1 crystals of reduction of $\mathrm{Cu}, \mathrm{Co}, \mathrm{Ni} ; 2$ - vitreous phase

From the data presented in Fig. 10, it can be concluded that the samples have a bright color corresponding to the salt solutions under study. On all three samples there is a clear vitreous phase of white color. With a reduction of flame, the reduction of $\mathrm{Cu}, \mathrm{Co}$, $\mathrm{Ni}$ occurs.

The microhardness was determined on a Vickers pyramid hardness machine NEXUS 4504 with a test load of 0.1 kilogram-force / $0.98 \mathrm{~N}$. Before testing, the fused surface was cut off by a diamond disc and roughnesses were poured with epoxy resin. And after its hardening the surface was ground. The sample of the prepared fused layer was tested for microhardness. The microhardness test results for the fused layer are shown in Table II.
TABLE II. THE MICROHARDNESS OF THE FUSED LAYER OF FINEGRAINED CONCRETE AFTER PLASMA-CHEMICAL MODIFICATION

\begin{tabular}{|c|c|}
\hline Name & \\
\hline $\begin{array}{c}\text { Fused layer of fine-grained concrete impregnated } \\
\text { with solutions of salts }\end{array}$ & $\begin{array}{c}\text { Microhardness, } \\
\text { HV }\end{array}$ \\
\hline Nickel $\mathrm{NiCl}_{2} \cdot 6 \mathrm{H}_{2} \mathrm{O}$ (State Standard 4038-79) & 708.78 \\
\hline Cobalt $\mathrm{CoCl}_{2} \cdot 6 \mathrm{H}_{2} \mathrm{O}$ (State Standard $\left.4525-77\right)$ & 856.76 \\
\hline Copper $\mathrm{CuCl}_{2} \cdot 2 \mathrm{H}_{2} \mathrm{O}$ (State Standard 4167-74) & 1300.63 \\
\hline
\end{tabular}

The data allow us to conclude that the microhardness of plasma-fused layers of fine-grained concrete is quite high. It is shown that the highest microhardness has a protectivedecorative coating with copper salts $\left(\mathrm{CuCl}_{2} \cdot 2 \mathrm{H}_{2} \mathrm{O}\right)$ and reaches $1300 \mathrm{HV}$.

\section{Conclusion}

The conducted researches made it possible to establish regularities in the formation of the structure of protectivedecorative coatings on concrete using dyeing metal salts. Using a plasma jet, one can regulate the medium, which will make it possible to expand the color gamut of coatings.

High microhardness of coatings obtained after plasmochemical modification of fine-grained concrete will improve its resistance to scratching and possible shock loads during operation. This will increase the reliability and durability of fine-grained concrete with protectivedecorative coatings.

\section{Acknowledgment}

The work is realized in the framework of the Program of flagship university development on the base of Belgorod State Technological University named after V.G. Shoukhov, using equipment of the High Technology Center at BSTU named after V.G. Shoukhov.

\section{References}

[1] M.V. Akulova, Yu.A. Shchepochkina, "New low-melting glazes for concrete", Glass and Ceramics, vol. 56 (3-4), pp. 127-128, March 1999.

[2] S.V. Fedosov, M.V. Akulova, Yu.A. Shchepochkina, "Tinting glaze with iron-containing compounds on nonfired inorganic materials", Glass and Ceramics, vol. 62 (1-2), pp. 30-31, January 2005.

[3] Yu.A. Shchepochkina, M.V. Akulova, S.V. Fedosov, "Use of waste in a vitreous coating for brick", Glass and Ceramics, vol. 57 (11-12), pp. 389, November 2000.

[4] V.S. Bessmertnyi, A.V. Simachev, N.M. Zdorenko, I.V. Rozdol'skaya, N.I. Min'ko, N.I. Bondarenko, D.O. Bondarenko, "Evaluation of the competitiveness of wall building materials with glassy protective-decorative coatings obtained by plasma fusing", Glass and Ceramics, vol. 72 (1-2), pp. 41-46, May 2015.

[5] N.I. Bondarenko, V.S. Bessmertnyi, I.A. Ilina, E.O. Gaschenko, "Glazing of concrete products using a low-temperature plasma torch", The Bulletin of BSTU named after V.G. Shukhov, vol. 2, pp. 124127, May 2012.

[6] K. Nassan, J. Shiever "Plasma torch preparation of high piriti jowohcontent tured silikat", S. Awer. Ceram. Soc. Bull, vol. 54, pp. $1004,1975$.

[7] K. Nassan, J. Shiever, T.J. Krause, "Preparation and fused silica containig aluminas", S. Awer. Ceram. Soc., vol. 58, pp. 461, 1975.

[8] G. Bolelli, V. Cannillo, T. Lusvarghi, T. Manfredini, C. Siligardi, C. Bartuli, A. Loreto, T. Valente, "Plasma - sprayed glass-ceramic 
coatings on ceramic tiles:nicrostructure, chemical resistanace and mechanical proprties", Jonrnal of the Eukopean Ceranic Sociaty, vol. 25 (11), pp. 1835-1853, 2005.

[9] G. Bolelli, L. Lusvarghi, T. Maufredini, C. Siligardi, "SiligardiInfluence of the manufacturing process of the crystallization behavior of a czs glass system", Journal of Non-Crystalline Solids, vol. 351 (30-32), 2005, pp. 2537-2546.

[10] S.V. Fedosov, M.V. Akulova, "Plasma metallization of concretes", Moscow: ASV, 2003

[11] M.V. Akulova "Fundamentals of technology of finishing and waterproofing materials", Ivanovo: IISI, 1991.

[12] V.F. Chernih, "Wall and finishing materials," Moscow: Rosagropromizdat, 1991. 